\title{
The Application of Streaming Media in the Construction of Network Teaching
}

\author{
Weichuan Zhuo* \\ Sanjia Technology Company, Xining 810000, China. E-mail: zhuoweichuan@163.com
}

Abstract: With the rapid development of current information science technology and computer network technology, online education has become an important learning direction for current learners. Online education is gradually becoming personalized, intelligent and professional, especially based on the development of streaming media technology. Under this premise, let the traditional text browsing and downloading technology be replaced. At present, people can use interaction to complete the sharing of information, video, audio and other resources, which also provides a huge space for the development of streaming media technology. At the same time, due to the continuous development of streaming media technology, great changes have taken place in the construction of my country's online education resource environment. Streaming media technology can not only be used for the transmission of network information, but also enable learners to exert greater initiative in the online learning process. The right to make the interaction between teachers and students more real-time and effective, which can effectively improve the efficiency of learners. Therefore, the research work of establishing a network teaching resource system based on the development of streaming media is very important.

Keywords: Streaming Media; Network Teaching; Construction; Application

\section{Introduction}

With the continuous development of technology and economy, network teaching has developed rapidly in recent years and has entered a new stage of development. In modern network education with computers as the main technology, the network transmission and download of video and audio is the main embodiment of today's network teaching. Through the transmission of audio and video, teaching efficiency is greatly improved, and time and space are saved. The application of streaming media technology in network teaching can transmit files more effectively and faster, and solve the shortcomings of slow transmission speed. This article mainly introduces the current situation of network teaching in our country, and based on streaming media technology, proposes corresponding solutions for distance teaching.

\section{Overview of online teaching resources}

For digital teaching materials used for online teaching resources to conduct teaching activities in a network environment, this teaching method and teaching resources include all information resources on the Internet that can help teaching activities. In other words, there are many forms of online teaching resources. It includes CAI teaching soft- 
ware and Internet-based multimedia teaching resources. Its acquisition channels are relatively abundant. Teachers canindependently conduct development and research, students can actively create, market purchases and network downloads. Online teaching resources are an important part of the modern online teaching process. They are of great value to the smooth development of modern education and the improvement of teaching quality. They can promote independent learning of students on the Internet and improve the teaching ability of faculty. To a large extent, the tracking of quality and achievement has the specific characteristics of digitization, scientification, standardization and dynamics of modern social information development. Online teaching resources have the following characteristics. First of all, the teaching resources are relatively sufficient, the teaching system model is no longer single, and the types are relatively rich. Online teaching resources integrate some relatively front-end teaching content, which can help learners obtain more and more information from abundant network resources related to learning content. Second, the learning method is variable, and the learning process is not restricted. The main reason is that students can use a lot of spare time to study, complete the download and preview of teaching resources, and help students solve practical problems in learning faster and more timely. Moreover, the learning process of students can realize remote communication without space restrictions, helping teachers and students to communicate better, and giving full play to the unique advantages of modern computer network information technology. In view of the characteristics of the current network teaching resources in our country, the realization of the rich application of network teaching resources and the construction of a rich treasure house of teaching resources in the modern teaching process are of great value to our country's network teaching work. The development of network teaching under the background of streaming media will make full use of the richness of modern network teaching resources, effectively improve the connotation of teaching content, and improve the main characteristics of single-form, poorly disseminated network teaching resources. Therefore, the application of streaming media in teaching resource system has important research value.

\section{Overview of the main situation of streaming media}

Specifically, streaming media technology is a multimedia file, which implements streaming technology to spread on the network. The video data and sound files are compressed and then placed on the server so that users can listen to and watch them while downloading. In addition, the new media dissemination method allows users to continue to download these files in the background while watching these files, thereby enhancing the user experience. This new application mode greatly reduces the time users wait to download full text from the Internet and provides users with greater convenience. In fact, the key technology of this technical system is compression coding technology. The basic principle is to reorganize the data structure of the file through a specific encoding method, delete some insignificant space, reduce the size of the file, and then divide the file into compressed packages to form a data stream, thereby converting the original complete multimedia file. It is a streaming media file with a streaming format. This new coding technology provides possibilities for the application of advanced streaming technology, and also brings greater convenience to people's daily work and life. In terms of composition, a complete streaming media system should include encoding tools, streaming media data, servers, networks and players.

\section{The status quo of online teaching in my country}

According to different educational objects, my country's online teaching can be divided into four stages: higher education, basic education, vocational education and early childhood education. In these four stages, the online teaching of higher education has the fastest growth. The state has approved many universities to conduct modern online teaching, and registered nationally recognized courses and other academic education. Basic education is mainly based on junior high school and high school education. It is mainly established by Internet companies and well-known educational institutions. Some online education courses, such as math, Chinese and English courses, are aimed at important test locations for high school and college entrance examinations and simulation experiments. Vocational education is the continuing education of this major, which mainly includes improving academic qualifications, facing the needs of 
new positions, new industries, etc., carrying out special vocational education and cultivating more professional talents. Early childhood education is mainly for children aged 3-8. It is mainly a multimedia preschool education software. The teaching courses are conducted in the form of some videos and animations to attract the attention of children. The traditional network teaching process is to use the server to transfer the complete video files to the file server, and students can only play these files after they are completely downloaded. This requires a lot of time to download files, and it is impossible to achieve simultaneous real-time broadcasting on the Internet. This is a problem in the process of remote real-time broadcasting on the Internet.

\section{Problems of streaming media in the construction of network teaching}

\subsection{Courses on demand}

The form of on-demand courses is to transmit various teaching contents to a streaming media server. Students can search various streaming files in the server. Students can search according to their specific needs and visit the corresponding server for targeted learning.

\subsection{Online live teaching}

In the past, most online teaching was recorded courses, while students watched videos to learn. The teaching content of the classroom can be broadcast live through network technology, so that students can watch the live broadcast in real time anywhere. This method avoids the troublesome storage of a large number of streaming media files. It can not only directly digitize audio and video, but also broadcast real-time document files and information on the electronic screen in real time. This method is of great help to the current online teaching and improves teaching efficiency. After the live broadcast, these digitized audio and video can be stored in streaming media, and students can watch on demand in the future.

\subsection{Remote collaboration}

This is a way of remote direct communication. It uses streaming video conferencing or video phone functions to allow teachers and students to communicate and discuss learning situations in different places. This is conducive to direct communication between teachers and students, which is not limited to face-to-face communication, breaks through geographical restrictions, and expands the scope of exchange groups.

\section{Application of streaming media in the construction of network teaching}

Streaming media is played in a media format on the network through streaming, so it is also called streaming media. Streaming media technology can compress continuous text information, sound, video, etc., and then place it on a network server to complete segmented transmission. Learners can combine the development and teaching of information technology to meet the actual needs of customers, can transmit all videos, download all audio materials, and then listen and play at any time. Based on this technology, the development of network teaching is more in line with actual needs, and network teaching resources have greater development advantages. As a modern education method, online courses are a teaching mode established in the Web environment. This model cannot exist independently of network hardware. Among them, resource construction is the main technical core, and teaching application is the main purpose. This determines that the quality of online resources directly affects the teaching effect and quality of online courses. Streaming media, as a main information form in the development and application of modern multimedia network information technology and multimedia technology, has enriched the content of network resources to a certain extent, increased the amount of information storage of network resources, and increased network resources. The transmission speed is fast, which indirectly helps students increase study time and improve study efficiency.

\subsection{Construction of streaming media resource library platform}


In the process of online course teaching, the construction of streaming media resource library platform is mainly constructed by video database, web server and streaming video server. On this platform, users can communicate in real time with the data information resource database through a browser. After initially understanding the resource information database information reflected in the browser, they can choose appropriate learning content to play and learn.

\subsection{File management of streaming media resource library}

After the construction of the streaming media application platform is completed, it is necessary to manage the network information resource library under the streaming media platform, upload the rich streaming media audio and video resources to the streaming media server, and classify them according to related content. The corresponding category is provided for the convenience of searching users. In addition, you need to enter file information and upload it to the complete resource database. The tree topology structure enriches the search methods and content, and effectively improves the user's query efficiency.

\subsection{Streaming media application in online courses}

Generally speaking, streaming media service platforms established by universities are mainly based on the browser/server model. At the same time, multiple technologies are applied to the development process. The background data is an application of SQLSEVER2008 to realize the richness of online courses in the context of streaming media applications. Users can order streaming media video resource library so that they can watch related learning content on streaming media players, or download it. This kind of online course learning mode is mainly suitable for teaching in different spaces and is not limited by time and place, and has played a greater role in the innovation of modern teaching methods.

\section{Conclusion}

Using streaming media technology for teaching can greatly increase students' interest in learning, and at the same time, it can transmit a large amount of information, improve teaching efficiency and teaching quality, and bring strong vitality to online education. The streaming media technology of online teaching meets the educational needs of different groups of people to a certain extent, and has a great effect on improving the quality of professional talents in our country. With the continuous development of the Internet, the role of streaming media technology in online teaching will become more and more important.

\section{References}

1. Ma H, Ye F. The application of streaming media technology in the construction of network teaching resources (in Chinese). Science \& Technology Information 2006; (11): 154.

2. Gao Y. Research on construction and application of network teaching resource library based on streaming media (in Chinese). Journal of Luohe Vocational and Technical College 2015; 14(2): 73-74.

3. Wan M. Discussion on the teaching application and importance of streaming media technology in university campus network. Wuxian Hulian Keji 2019; 16(10): 128-129.

4. Xie H. Application of streaming media technology in campus network teaching. Value Engineering 2012; 31(9): 133. 